\title{
Abuso en la prescripción de fluoroquinolonas para el tratamiento de infecciones urinarias
}

\section{Fluoroquinolone prescription abuse in urinary tract infections}

Alejandro E. Macías Hernández
Las fluoroquinolonas, o quinolonas, son antibióticos sintéticos que inhiben las girasas del ADN. ${ }^{1}$ Entre los más prescritos se encuentran: ácido nalidíxico, ciprofloxacino, norfloxacino, ofloxacino, levofloxacino y moxifloxacino. Tienen la capacidad de absorberse por vía oral y se distribuyen ampliamente en todos los tejidos; puesto que alcanzan una concentración urinaria alta, se indican en diversas infecciones urológicas. En relación con las primeras, las "nuevas quinolonas" (levofloxacino o moxifloxacino) tienen actividad contra patógenos de la vía aérea, como neumococo o mycoplasma; sin embargo, carecen de ventajas contra microorganismos gramnegativos. Anteriormente las quinolonas solían indicarse para el tratamiento de microorganismos resistentes a los antibióticos, pero en los últimos años han dejado de prescribirse debido al abuso indiscriminado en medicina humana y veterinaria. Es la historia que se repite: cuando "acorralamos"
Investigador nivel III, SNI Conacyt; internista e infectólogo, Universidad de Guanajuato, México.

Correspondencia:

Alejandro E. Macías Hernández aaeemmhh@yahoo.com Twitter: @doctormacias a las bacterias, se defienden y logran múltiples salidas. En la actualidad, la resistencia a las quinolonas es alta, incluso va en aumento en todo el mundo para prácticamente todas las especies a las que eran efectivas. ${ }^{1}$

Cuando estuvieron disponibles comercialmente se consideraron antibióticos seguros, por lo que alcanzaron gran popularidad. Sin embargo, con los años e informes posmercadeo se hicieron evidentes sus complicaciones: rotura espontánea del tendón de Aquiles o de tendones del hombro o la mano, neuropatía periférica, rabdomiólisis, síndrome de Stevens-Johnson, psicosis e hipoglucemia. Por eso, recientemente la FDA emitió una alerta para dejar de prescribir, en todo lo posible, las quinolonas como tratamiento de primera línea. $^{2}$

Las quinolonas suelen prescribirse para el tratamiento de enfermedades gastrointestinales y 
es común el abuso de su indicación a pacientes con cualquier tipo de diarrea, al igual que para infecciones respiratorias virales agudas, particularmente levofloxacino y moxifloxacino. Sin embargo, una de las áreas de mayor abuso es la Urología, donde se indica no solo para infecciones agudas sino como estrategia preventiva en procedimientos quirúrgicos o bacteriuria asintomática, incluso la relacionada con sondas a permanencia.

Desde su desarrollo, pocas bacterias se encontraron resistentes a las quinolonas, hasta que comenzaron a indicarse en aves de corral en 1995. Por ello y por el abuso en la práctica clínica, la situación se ha vuelo catastrófica. En agosto de 2018, el Plan Universitario de Control de la Resistencia Antimicrobiana "PUCRA" de la UNAM analizó, entre otros, la resistencia a las quinolonas en 14 instituciones de salud de la República Mexicana. Si consideramos como centinela de esta resistencia a Escherichia coli podemos comprender la gravedad de la situación: en 5066 cepas de orina y 699 de sangre, la resistencia superó $60 \%$ de los casos. ${ }^{3}$ ¿Cómo justificar entonces que, incluso los especialistas prescriban estos antibióticos como primera línea en infecciones urinarias o como profilaxis de procedimientos quirúrgicos?

Los datos son contundentes, la información actual en México y el mundo señala:
1. Las quinolonas han dejado de ser agentes de primera línea para el tratamiento y prevención de infecciones urinarias.

2. Los agentes patógenos de las vías urinarias muestran alta resistencia a las quinolonas; por tanto, deben indicarse como última opción y solo si se cuenta con el estudio de sensibilidad a los antibióticos.

3. Las quinolonas no deben prescribirse como tratamiento profiláctico en biopsias y otros procedimientos quirúrgicos relacionados con la vía urinaria.

4. Las quinolonas no son antibióticos seguros, provocan múltiples complicaciones y siempre debe evaluarse su potencial beneficio.

En fin, honremos la evidencia y abandonemos el abuso de la prescripción de las quinolonas en el tratamiento y prevención de las infecciones relacionadas con la vía urinaria.

\section{REFERENCIAS}

1. Aldred KJ, Kems RJ, Osheroff N. Mechanism of quinolone action and resistance. Biochemistry. 2014;53:1565-74.

2. FDA News release. https://www.fda.gov/newsevents/ newsroom/pressannouncements/ucm612995.htm Consultado septiembre 30, 2018.

3. Graue-Wiechers E, et al. http://www.puis.unam.mx/slider_docs/reporte-ucradigital.pdf Consultado septiembre $30,2108$. 